\title{
Crystal structures of the human Dysferlin inner DysF domain
}

\author{
Altin Sula ${ }^{1}$, Ambrose R Cole ${ }^{1}$, Corin Yeats ${ }^{2,3}$, Christine Orengo ${ }^{2}$ and Nicholas H Keep ${ }^{1 *}$
}

\begin{abstract}
Background: Mutations in dysferlin, the first protein linked with the cell membrane repair mechanism, causes a group of muscular dystrophies called dysferlinopathies. Dysferlin is a type two-anchored membrane protein, with a single C terminal trans-membrane helix, and most of the protein lying in cytoplasm. Dysferlin contains several C2 domains and two DysF domains which are nested one inside the other. Many pathogenic point mutations fall in the DysF domain region.

Results: We describe the crystal structure of the human dysferlin inner DysF domain with a resolution of 1.9 Ångstroms. Most of the pathogenic mutations are part of aromatic/arginine stacks that hold the domain in a folded conformation. The high resolution of the structure show that these interactions are a mixture of parallel ring/guanadinium stacking, perpendicular $\mathrm{H}$ bond stacking and aliphatic chain packing.

Conclusions: The high resolution structure of the Dysferlin DysF domain gives a template on which to interpret in detail the pathogenic mutations that lead to disease.
\end{abstract}

Keywords: Dysferlin, Limb girdle muscular dystrophy 2B, Arginine-tryptophan stacking, DysF domain, Crystal structure

\section{Background}

Dysferlinopathies are a group of autosomal recessive inherited late onset progressive muscular dystrophies caused by malfunction of dysferlin protein. Mutations in the dysferlin protein cause three phenotypes called limb girdle muscular dystrophy type 2B [1], Miyoshi myopathy [2], and distal anterior compartment myopathy [3]. Dysferlin is not a part of the dystrophin-glycoprotein complex, but its function is linked with calcium-activated membrane repair caused by fusing aggregated intracellular vesicles with the sarcolemma at the site of injury [4-6]. The mechanism of membrane repair is not yet determined in detail and the specific role of dysferlin needs to be defined at the structural level.

Dysferlin, a member of the ferlin protein family, is a type II anchored membrane protein with a single $C$ terminal helix buried in the membrane. Ferlin proteins are defined as containing four or more $\mathrm{C} 2$ domains and a $\mathrm{C}$ terminal trans-membrane helix. There are 6 ferlin proteins expressed in human; dysferlin, myoferlin, otoferlin, Fer1L4, Fer1L5, and Fer1L6 [7]. Myoferlin is the most similar paralogue to dysferlin. Both proteins are predicted to have the same

\footnotetext{
* Correspondence: n.keep@mail.cryst.bbk.ac.uk

${ }^{1}$ Crystallography, Biological Sciences, Institute for Structural and Molecular Biology, Birkbeck University of London, Malet Street, London WC1E 7HX, UK Full list of author information is available at the end of the article
}

domain composition with overall sequence identity of $56 \%$. Dysferlin is expressed in most tissues but is found in abundance in skeletal muscle, heart, brain and placenta.

The multiple domain architecture of dysferlin was analysed by a combination of Gene3D [8], SMART [9] and Pfam [10] domain family resources. The domain architecture is predicted to consist of seven $\mathrm{C} 2$ domains (C2A to $\mathrm{C} 2 \mathrm{G}$ ), three Fer domains (FerA, FerB and FerI), two DysF domains, one nested inside the other, and a $\mathrm{C}$ terminal trans-membrane domain (Figure 1a). C2 domains are found in hundreds of proteins and many are known to bind to phospholipids or proteins, often in a calcium dependent manner [6]. In dysferlin and myoferlin C2A binds to phospholipids in a calcium dependent manner. $[11,12]$. The other $\mathrm{C} 2$ domains do not show calciumdependent binding to lipids, but do show some calcium independent binding to phospholipids [11,12]. The other C2 domains are believed to interact with dysferlin binding proteins or to be involved in dimerisation [13]. Recently it has been shown that there is a minor variant of the dysferlin $\mathrm{C} 2 \mathrm{~A}$ domain, C2Av1, that does not bind via calcium [14]. Crystal structures of the canonical and variant structures of $\mathrm{C} 2 \mathrm{~A}$ show conservation of structure, even where the sequence is not conserved. Biophysical characterisation of the interactions with phospholipids and calcium 


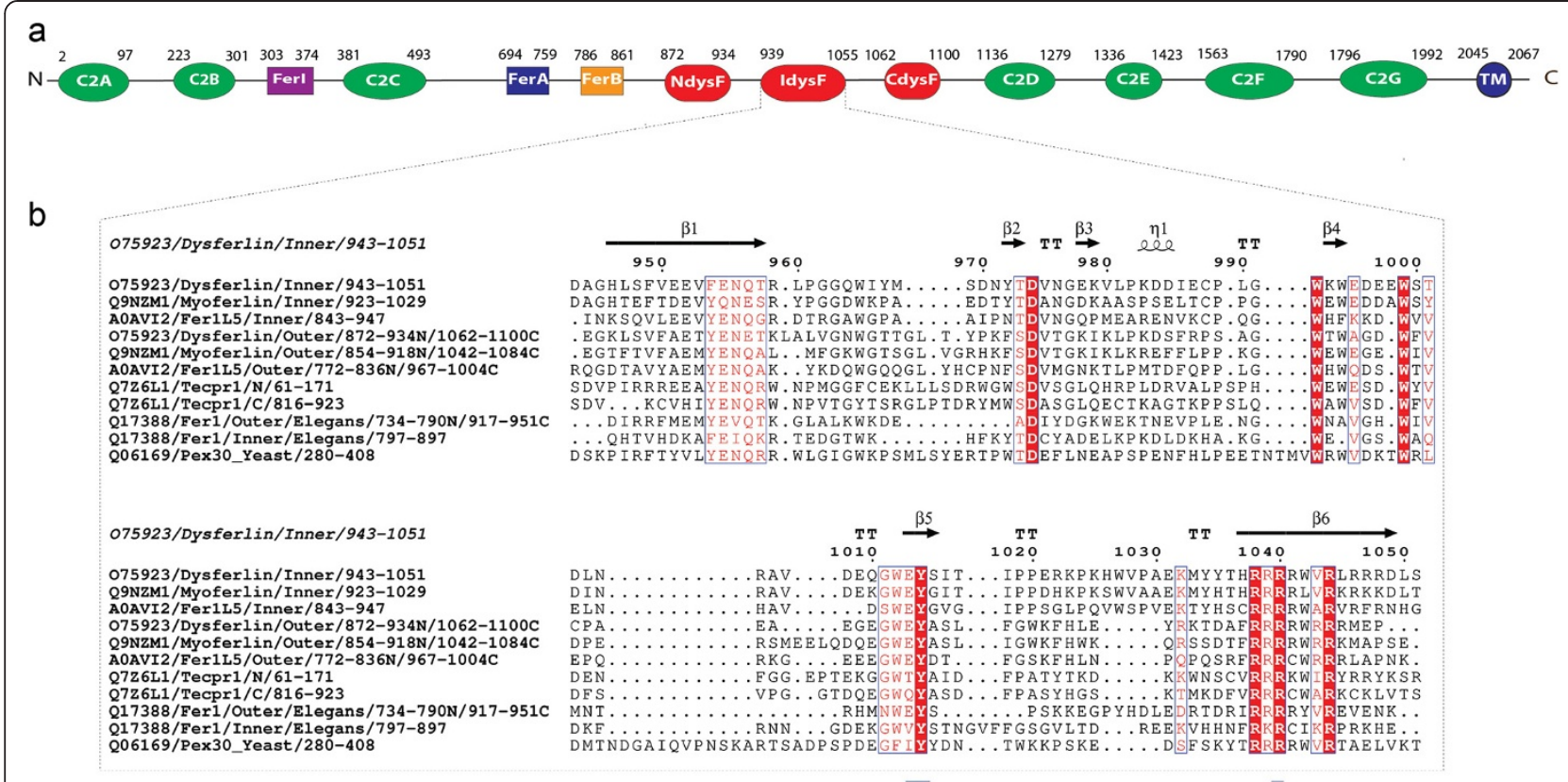

Figure 1 Domain organisation of dysferlin and alignment of DysF domains. a) Multiple domain architecture of human dyferlin protein (Gene3D and pFam). b) Multiple sequence alignment of inner and outer DysF domain of Human Myoferlin, Dysferlin, Fer115; human Tecpr1 DysF domains; inner and outer DysF domain of C. elegans Ferl protein, and Yeast Pex30 DysF domain (aligned with mafft and drawn with ESPript).

indicate that the $\mathrm{C} 2 \mathrm{~A}$ and $\mathrm{C} 2 \mathrm{Av} 1$ domains are highly conformationally flexible [14]. The Fer domains (FerA, FerB, and FerI) are short conserved regions found only in the ferlin protein family and are not yet shown to be folded domains.

Dysferlinopathy causing mutations are dispersed throughout the length of the protein, but many fall in the DysF domains $[15,16]$. One DysF domain is inserted into the other DysF domain, by gene duplication, forming an inner DysF domain and a two part ( $\mathrm{N}$ terminal and $\mathrm{C}$ terminal) outer DysF domain [17]. The function of the DysF domain is unknown. The human myoferlin (dysferlin paralogue) inner DysF domain structure was solved by Nuclear Magenetic Resonance (NMR) and showed a novel fold. This consists of two long beta strands connected by a long loop that caps the sheet edges in certain sections [18]. The structure contains arginine/tryptophan stacks that holds the fold together and are largely conserved throughout DysF domain sequences (Figure 1b).

In this study, we have determined the three dimensional structure of human dysferlin inner DysF domain by X-ray crystallography at $1.9 \AA$. This is the first DysF domain crystal structure.

\section{Results and discussion}

\section{Structure characterisation}

The structure was solved by molecular replacement with the NMR structure of the inner DysF of myoferlin [18]. The sequence identity between the inner DysF domain in dysferlin and myoferlin is 61\% (Figure 1b). Most datasets that were collected, processed and refined in space group $\mathrm{P} 2{ }_{1} 3$ (cubic), with the best resolution dataset diffracting to $1.9 \AA$. A single dataset was collected in a different space group $\mathrm{P} 2{ }_{1} 2_{1} 2_{1}$ (orthorhombic) to $2.2 \AA$. The crystal packing is almost the same in the two forms, but the distortions of the perfect cube in the orthorhombic structure means the monomers of the crystallographic trimer in the cubic crystals are no longer identical (Figure 2a, b). This leads to some of the flexible regions (eg residues 965-671) being more visible in some chains with the orthorhombic data. Except where stated otherwise the analysis is based on the single chain in the $1.9 \AA$ structure. Statistics for both datasets are summarised in Table 1 and have been deposited in the Protein Data Bank [PDB:4CAH][PDB;4CAI].

The inner DysF domain construct starts at residue Met942 and ends at Gln1052 and has a Ser on the N terminus from the TEV protease site. The additional Ser, Met942 and Gln1052 are not visible in the structures. The main secondary structure consists of two long antiparallel $\beta$-strands, one at each terminus ( $\mathrm{N}$ terminus 946-958, C terminus 1036-1049). These $\beta$-strands are connected with a long loop (77 residues). The loop caps the edge of the $\mathrm{N}$ terminal $\beta$-strand with main chain hydrogen bonds from residues 966, 971 and 973. The $C$ terminal $\beta$-strand is capped with main chain hydrogen bonds from residues 993, 995, 996, 1000, 1013 and 1015. These give short $\beta$ strands within the linking loop. There is also a single turn of $3_{10}$ helix from 983 to 986 (Figures 1b, 2a). This 


\section{a}

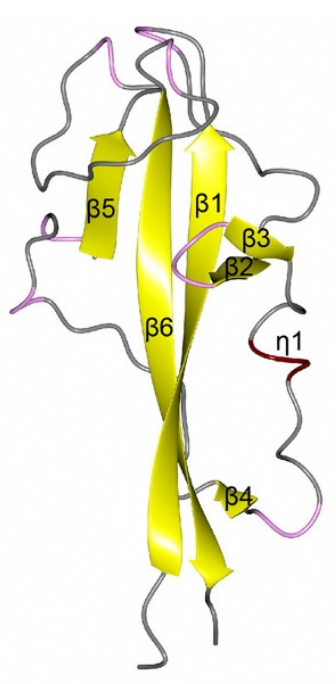

C

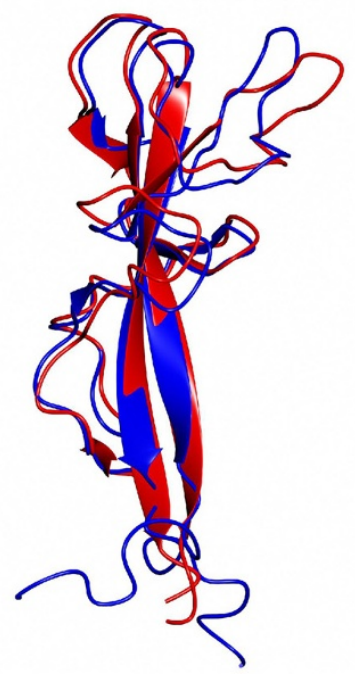

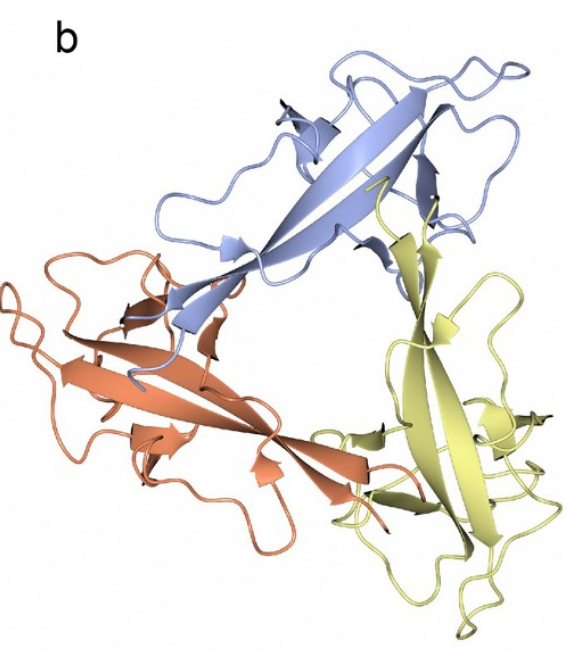

d

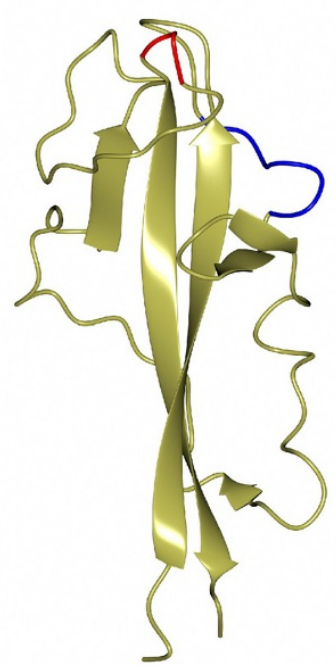

Figure 2 Comparison of DysF domain structures. Ribbon presentation of a) $\mathrm{P} 2_{1} 3$ asymmetric unit (the beta strands are coloured in yellow, 3 turn in pink, 4 turn in tan and no structure in grey) and $\mathbf{b}) \mathrm{P}_{2} 2_{2} 2_{1}$ asymmetric unit coloured by chain. c) Superimposed models of myoferlin NMR DysF domain (blue) with dysferlin crystal DysF domain (red). d) Two areas of very high B factor in dysferlin DysD domain coloured in blue (965-971) and red (1018-1021). Orientation as in Figure 2a). Figure drawn with CCP4mg [19].

secondary structure is also conserved in the NMR structure of the myoferlin inner DsyF domain [18].

The structure is highly conserved between independent copies in the crystals. The crystallographic trimer of the $\mathrm{P} 2{ }_{1} 3$ crystal superimposes onto the trimer in the $\mathrm{P} 2{ }_{1} 2_{1} 2_{1}$ asymmetric unit with an RMSD Calpha of $0.89 \AA$ over 326 residues of the trimer. The four individual chains from the two assymetric units superimpose no worse than $0.79 \AA$ Calpha RMSD over 108 residues for any pair. The conservation with the NMR structure of myoferlin is also extremely high with a Calpha RMSD of $1.78 \AA$ over 106 residues being the worst and $1.45 \AA$ over 103 residues being the best of the 20 models (Figure 2c). The biggest variation between dysferlin models is between 965 and 971 and 1018 and 1021 (Figure 2d). These are also the regions with the highest temperature (B) factors in dysferlin, the regions with the largest RMS between NMR models in myoferlin, as can be seen from the CING database [20,21], and the regions that differ most between dysferlin and myoferlin. However the region from 958-960 also has high $\mathrm{B}$ factors, while conserving the backbone trace between structures quite well.

The trimer (with 9 phosphates) is predicted to be the stable assembly by PDBePISA [22]. Formation of the assembly buries a total $5250 \AA^{2}$. The interface between the protein chains (repeated 3 times in the trimer) forms 5 (pisa) - 7(ccp4mg) hydrogen bonds and 3 salt bridges. Three of these are mainchain-mainchain, with $\beta 3$ forming intermolecular $\beta$ strand links to $\beta 1$ as well as the intramolecular $\mathrm{H}$ bonds to $\beta 6.2 \mathrm{H}$ bonds are mainchain- 
Table 1 Data collection and refinement statistics of the dysferlin inner DysF domain

\begin{tabular}{|c|c|c|}
\hline Data collection & PDB 4CAI & PDB 4CAH \\
\hline Wavelength (Å) & 1.037530 & 0.97718 \\
\hline Space group & $\mathrm{P} 22_{1} 2_{2}$ & $\mathrm{P} 2,3$ \\
\hline \multicolumn{3}{|l|}{ Unit-cell parameters } \\
\hline$a, b, c(\AA)$ & $74.5,77.47,79.89$ & $75.95,75.95,75.95$ \\
\hline$a, \beta, \gamma\left(^{\circ}\right)$ & $90,90,90$ & $90,90,90$ \\
\hline Resolution range $(\AA)$ & $50-2.2(2.27-2.20)$ & $53.7-1.9(1.94-1.9)$ \\
\hline Total number of observation & $78153(6922)$ & $115092(7574)$ \\
\hline Total number unique & $24062(2084)$ & $11803(760)$ \\
\hline Completeness & $99.8(99.9)$ & $100.0(100.0)$ \\
\hline Multiplicity & $3.2(3.3)$ & $9.8(10)$ \\
\hline$<\mid / \sigma(I)>$ & $12.4(2.3)$ & $30.5(3.5)$ \\
\hline$C C(1 / 2)$ & $0.976(0.758)$ & $1.00(0.847)$ \\
\hline$R_{\text {merge }}$ & $0.045(0.466)$ & $0.044(0.667)$ \\
\hline Solvent content (\%) & 56.8 & 53.0 \\
\hline Molecule per ASU & 3 & 1 \\
\hline Wilson B factor $\left(\AA^{2}\right)$ & 42.2 & 31.05 \\
\hline \multicolumn{3}{|l|}{ Refinement } \\
\hline Resolution range $(\AA)$ & $44.57-2.2$ & $53.7-1.9$ \\
\hline$R_{\text {work }}$ & $0.1858(0.2457)$ & $0.1775(0.1932)$ \\
\hline$R_{\text {free }}$ & $0.2271(0.3102)$ & $0.1908(0.2283)$ \\
\hline Reflection, working & 22764 & 11220 \\
\hline Reflection, free & 1206 & 549 \\
\hline Average B factor & 61.0 & 42.0 \\
\hline Rmsd bond angle & 1.358 & 1.76 \\
\hline Rmsd bond length $(\AA)$ & 0.011 & 0.015 \\
\hline \multicolumn{3}{|l|}{ Ramachandran Analysis } \\
\hline Preferred region (\%) & 96.7 & 95.2 \\
\hline Allowed region (\%) & 2.4 & 2.9 \\
\hline Outliers (\%) & 0.9 & 1.9 \\
\hline
\end{tabular}

Values in parentheses refer to the highest resolution shell.

$\mathrm{R}_{\text {merge }}=\Sigma(|-\langle|>) / \Sigma<\mid>$.

$R_{\text {work }}=\Sigma\left(\left|F_{\text {obs }}\right|-\left|F_{\text {calc }}\right|\right) / \Sigma\left|F_{\text {obs }}\right|$ for $95 \%$ of data. Rfree is the same equation for $5 \%$ of the data excluded from refinement.

sidechain and the others are sidechain-sidechain. Indeed the formation of $\beta 3$ is probably driven by the trimerisation. The relatively low B factor in this side of the loop may be partially caused by this packing. We have no evidence from gel filtration or NMR spectroscopy (data not shown) for the existence of a trimer, nor is there any likely way to invoke a trimer in vivo. There are two DysF domains in dysferlin and the reported oligomeric state of the full length protein is a dimer. Therefore two or four DysF domains seems more likely higher order assemblies, although extending the beta sheet either with other DysF domains or other proteins does seem to be a likely method of interaction.

\section{Arginine/tryptophan (R/W) stacks}

As reported for the myoferlin inner DysF domain [18], the dysferlin DysF domain is held together by arginine/aromatic sidechain stacking. Superficially there is a stack of arginines and tryptophans which runs the entire length of one face of the beta sheet, and a single small group on the other face (Figure 3a). However, at the good resolution of these crystal structures, we can give a much confident description of the exact nature of the interactions. In particular arginines can interact with aromatics either in a stacked (ie with the guanadinium parallel to the aromatic ring- above the six membered ring) [23] or in an $\mathrm{H}$ bond (with the amino group pointing at the ring and the guanadinium plane perpendicular to the aromatic ring). Theoretical calculations favour the $\mathrm{H}$ bond arrangement in vacuum but the stacked arrangement in water [24]. We do see both these types of interaction but a number of the arginine-guanadinium groups do not lie above the centre of aromatic ring. In fact the atlas of sidechain interactions $[25,26]$, does not have the Arg - Trp pairs above the centre of the ring in most of the clusters. Only one cluster lies above the 6 membered ring. In four of the six cases the guanadiniums lie above or beyond the NE-CZ containing edge of the ring and in one case beyond the opposite edge of the indole. In these cases there is still a hydrophobic interaction of the aliphatic sidechain with the ring and the guanadinium is available to form other H-bonds. A working definition of aliphatic stacking is that at least two side chain atoms are within $3.8 \AA$ of Trp ring atoms (the CH2CHar Van der Waals radii add up to 3.74 $\AA$ [27]).

The details of the R/W interactions are laid out in Table 2 and examples shown in Figure 3. The analysis shows that in fact there is not one continuous stack, but three on one face of the sheet. R1046 is to one side of W994, with only one non- $\mathrm{H}$ atom within $3.8 \AA$. Instead Cys 988 forms an aromatic $\mathrm{H}$ bond interaction with W994. The second break occurs between, R1040 and W1042, where both side chains hydrogen bond to E955, but there is no direct interaction between the two. On the other face R1039 stacks with both F954 and W1027. Most but not all the stacking interactions are conserved in the myoferlin inner domain, but the NMR structure does not define which mode of packing is taking place. By sequence homology most of these interactions would be found in the dysferlin outer dysf domain (sequence identity 32\%). The inner dysf domain of myoferlin lacks equivalents of $\mathrm{K} 983$ and W1042, although the overall fold is well conserved; conversely the outer dysferlin dysF domain lacks an equivalent of C988 and R1048, so in both cases the stacks will be a bit shorter.

\section{Dysferlinopathy mutations}

There are 15 missense mutations in the inner dysferlin domain reported in the Leiden dysferlin mutation database $[15,16]$. These are summarised in Table 3 which 


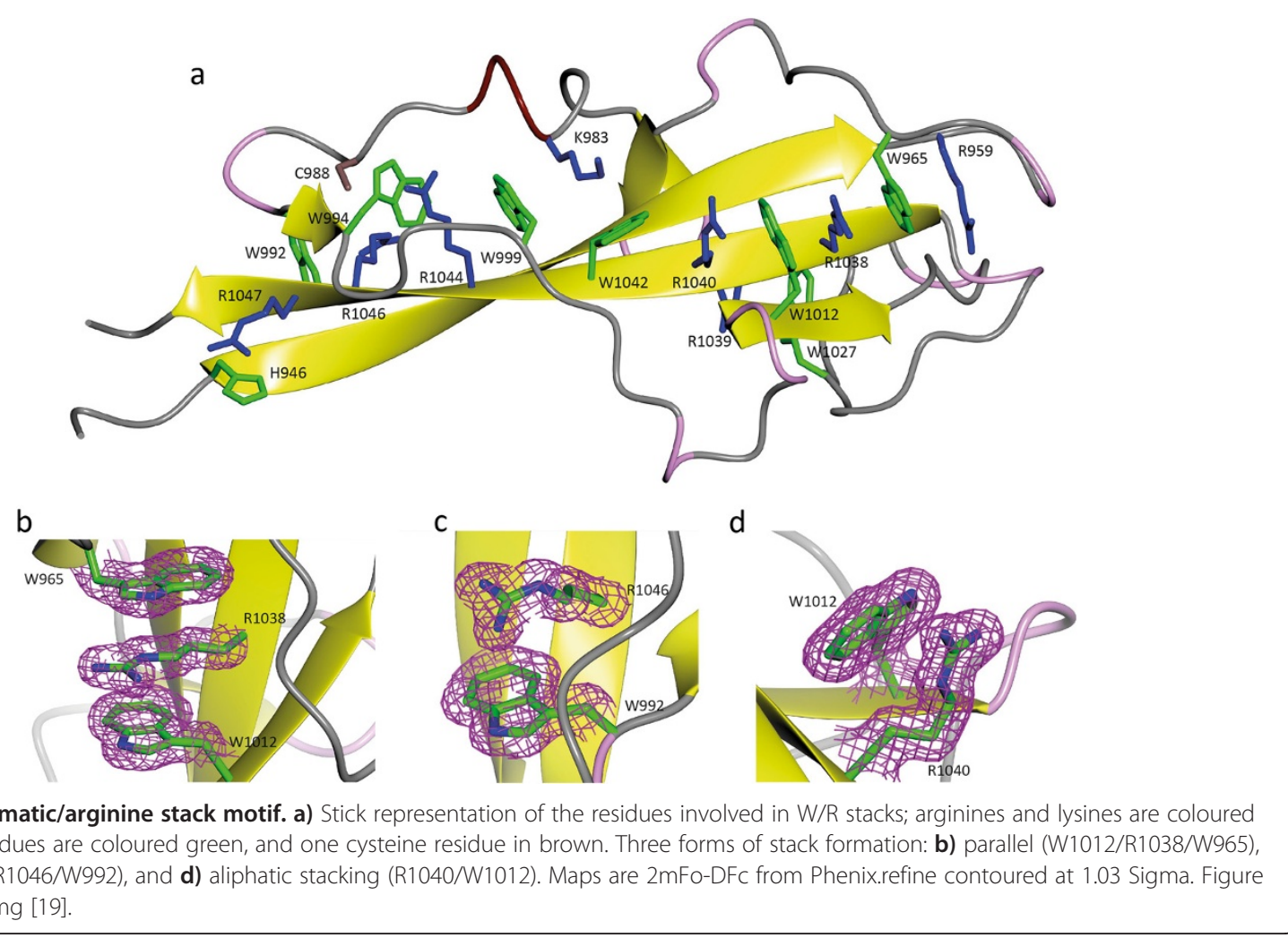

summarises the position. Figure 4 shows position of all the point mutations and close up views of the three most reported mutations. The three most frequent mutations disrupt the $\mathrm{R} / \mathrm{W}$ stacks and are likely to lead to a less stable or possibly unfolded domain. The unfolded domain may lead to degradation of the entire dysferlin protein. It is also notable that there are several surface residues mutated, although in this very flat domain nearly every residue contributes to the surface, which may indicate that the DysF domain is involved in protein-protein interactions.

\section{Conclusions}

The structure of the inner DysF domain of dysferlin confirms the unusual fold of this domain first seen in the myoferlin homologue. The high resolution of the structure allows detailed analysis of the interactions forming the R/W stacking seen in this domain. It also provides a better model for understanding the disease causing point mutations in this domain seen in dysferlin patients. The most common mutations will disrupt the $\mathrm{R} / \mathrm{W}$ stacking, making the domain more unstable or inherently unfolded, probably enhancing the degradation of the protein. Some of the dysferlin mutants map to the surface, implying that proteinprotein interactions may have a role in the function of this domain.

\section{Methods}

\section{Protein preparation}

Human dysferlin cDNA (Jain Foundation) was used to amplify the DNA encoding for the residues 943-1052. The human dysferlin inner DysF domain was cloned into pNic28Bsa4 plasmid (supplied by Dr Opher Gileadi of the Structural Genomics Consortium), which is a modified pET28a plasmid that allows ligation independent cloning [48]. The vector contains an $\mathrm{N}$ terminal histidine tag followed by a TEV protease cleavage site. The cloned sequence was confirmed by DNA sequencing and the plasmid transformed into E. coli strains Rosetta 2 (DE3) cells. One fresh colony was inoculated into $100 \mathrm{ml}$ of Luria Broth media (LB) and the culture was grown overnight. $8 \times 500 \mathrm{ml}$ of LB were inoculated with $1 \%$ of overnight culture and incubated at $37^{\circ} \mathrm{C}$ until the optical density reached 0.5 at a wavelength of $600 \mathrm{~nm}$. Then the cultures were induced with $0.5 \mathrm{mM}$ of IPTG and incubated at $18^{\circ} \mathrm{C}$ for 20 hours. Cells were collected by centrifuging at $4^{\circ} \mathrm{C}$ at $4000 \mathrm{rpm}$ for 20 minutes and resuspended in binding buffer (20 mMTris, pH 7.5, $500 \mathrm{mM} \mathrm{NaCl}, 20 \mathrm{mM}$ imidazole, $10 \mathrm{mM}$ 2-mercaptoethanol). The cells were stored at $-20^{\circ} \mathrm{C}$. After incubating with EDTA free protease inhibitor cocktail (Roche Applied Science, Switzerland), $0.1 \%$ Triton X-100 and DNAseI on ice for 30 minutes, the cells were sonicated at $20 \mathrm{~W}$ output for 4 minutes of 4 second on/off pulses for three cycles on ice and then 
Table 2 Aromatic arginine stack interactions in DysF domains

\begin{tabular}{|c|c|c|c|c|c|}
\hline Stack & $\begin{array}{l}\text { Dysferlin } \\
\text { inner domain }\end{array}$ & W/R type & Interactions & $\begin{array}{l}\text { Myoferlin inner domain equivalent } \\
\text { (Residue mentioned in interaction) }\end{array}$ & $\begin{array}{l}\text { Outer Dysferlin } \\
\text { DysF equivalent }\end{array}$ \\
\hline \multirow[t]{4}{*}{1} & \multirow[t]{4}{*}{ R1048 } & \multirow[t]{4}{*}{ Aliphatic W992 } & $\begin{array}{l}\text { Planar interaction to Y1034 in } \\
\text { crystal contact }\end{array}$ & \multirow[t]{4}{*}{ K1029 } & \multirow[t]{4}{*}{ P1100 } \\
\hline & & & $\begin{array}{l}\text { H Bond to Q1010 in crystal } \\
\text { contact }\end{array}$ & & \\
\hline & & & $\begin{array}{l}\text { Interacts with crystallisation } \\
\text { phosphate }\end{array}$ & & \\
\hline & & & $\begin{array}{l}\text { Guanadinium Beyond NH/CZ } \\
\text { of W992 }\end{array}$ & & \\
\hline 1 & W992 & & $\begin{array}{l}\mathrm{H} \text { bonds to crystallisation } \\
\text { phosphate }\end{array}$ & W973 & W924 \\
\hline \multirow[t]{3}{*}{1} & \multirow[t]{3}{*}{ R1046 } & \multirow[t]{3}{*}{ Perpendicular W992 } & $\begin{array}{l}\mathrm{NH} \text { points to } 6 \text { membered ring } \\
\text { of W992 }\end{array}$ & \multirow[t]{2}{*}{ R1027 } & \multirow[t]{2}{*}{ R1096 } \\
\hline & & & $\begin{array}{l}\mathrm{H} \text { bonds to crystallisation } \\
\text { phosphate }\end{array}$ & & \\
\hline & & & $\mathrm{H}$ bond to E951 & (D392) & (A879) ?E880 \\
\hline \multirow[t]{3}{*}{2} & C988 & & $\begin{array}{l}\mathrm{H} \text { bond to } 5 \text { membered ring } \\
\text { of W994 }\end{array}$ & C969 & P920 \\
\hline & W994 & & & W975 & W926 \\
\hline & R1044 & $\begin{array}{l}\text { Planar W994/ } \\
\text { Aliphatic W999 }\end{array}$ & $\begin{array}{l}\text { Planar stack above } 5 \text { membered } \\
\text { ring W994 }\end{array}$ & R1025 & R1096 \\
\hline \multirow[t]{2}{*}{2} & \multirow[t]{2}{*}{ W999 } & & $\begin{array}{l}\text { R1044 guanadinium is beyond NE/ } \\
\text { CZ edge }\end{array}$ & \multirow[t]{2}{*}{ W980 } & \multirow[t]{2}{*}{ W930 } \\
\hline & & & $\begin{array}{l}\text { Aliphatic interaction with side } \\
\text { chain of K983 }\end{array}$ & & \\
\hline 2 & K983 & & $\begin{array}{l}\text { Just over } 4 \AA \text { above } 6 \text { membered } \\
\text { ring of } \mathrm{W} 1042\end{array}$ & P964 & K915 \\
\hline 2 & W1042 & & $\mathrm{H}$ bond to E955 & L1023 (Q936) & W1094 (E883) \\
\hline \multirow[t]{2}{*}{3} & \multirow[t]{2}{*}{ R1040 } & \multirow[t]{2}{*}{ Aliphatic W1012 } & $\mathrm{H}$ bond to E955 & \multirow[t]{2}{*}{ R1021 (Q396) } & \multirow[t]{2}{*}{ R1092 (E883) } \\
\hline & & & $\begin{array}{l}\text { Guanadinium Beyond NE-CZ of } \\
\text { W1012 }\end{array}$ & & \\
\hline 3 & W1012 & & & W993 & W1069 \\
\hline \multirow[t]{2}{*}{3} & \multirow[t]{2}{*}{ R1038 } & Planar W1012 & $\begin{array}{l}\text { Planar stack to } 5 \text { membered ring } \\
\text { of W1012 }\end{array}$ & \multirow[t]{2}{*}{ R1019 } & \multirow[t]{2}{*}{ R1090 } \\
\hline & & Planar W965 & $\begin{array}{l}\text { Planar stack to } 5 \text { membered ring } \\
\text { of W965 }\end{array}$ & & \\
\hline 3 & W965 & & $\begin{array}{l}\mathrm{H} \text { bond to major conformation of } \\
\text { E1031 }\end{array}$ & W946 (E1012) & W894 \\
\hline \multirow[t]{2}{*}{3} & \multirow[t]{2}{*}{ R959 } & Aliphatic W965 & $\begin{array}{l}\text { Guanadinum Beyond NE-CZ of } \\
\text { W965 }\end{array}$ & \multirow[t]{2}{*}{ R940 } & \multirow[t]{2}{*}{ K887 } \\
\hline & & & $\begin{array}{l}\mathrm{H} \text { bonds to major and minor } \\
\text { conformations of E1031 }\end{array}$ & & \\
\hline \multirow[t]{5}{*}{ Opposite Face } & F954 & & & Y935 & Y882 \\
\hline & \multirow[t]{3}{*}{ R1039 } & Planar F954 & Close to planar Stack above F954 & R1020 & R1090 \\
\hline & & Planar W1027 & $\mathrm{H}$ bond to E1013 & \multirow[t]{2}{*}{ (E994) } & \multirow[t]{2}{*}{$($ E1070) } \\
\hline & & & $\begin{array}{l}\text { Planar Stack above } 5 \text { membered ring } \\
\text { of W1027 closer to NE than centre }\end{array}$ & & \\
\hline & W1027 & & & W1008 & Unclear \\
\hline
\end{tabular}

centrifuged at 48,000 g for 1 hour. The protein lysate was applied to a HisTrap (GE Healthcare) affinity column. The column was washed with binding buffer for
10 column volumes and the protein eluted in $20 \mathrm{mM}$ Tris, $\mathrm{pH}$ 7.5, $500 \mathrm{mM} \mathrm{NaCl}, 500 \mathrm{mM}$ Imidazole, $10 \mathrm{mM}$ 2-mercaptoethanol buffer. The eluents containing the 
Table 3 List of pathogenic missense mutations in the inner dysF domain taken from the Leiden database [16]

\begin{tabular}{|c|c|c|c|c|c|}
\hline Residue & Disease & Number of reports & References & Role of residue & Conservation score \\
\hline Arg959Trp & LGMD2B \& MM & 25 & {$[28-34]$} & In Stack 3 & 0.522 \\
\hline Met968Leu & LGMD2B & 1 & [35] & In loop. Poorly defined in structure and surface exposed & 0.281 \\
\hline Trp992Arg & LGMD2B \& MM & 2 & {$[36]$} & In Stack 1 & 1.000 \\
\hline Trp999Cys & LGMD2B \& MM & 24 & {$[35-40]$} & In Stack 2 & 1.000 \\
\hline Glu1009Lys & $?$ & 1 & [16] & Surface exposed in loop. Close to phosphate in crystal & 0.411 \\
\hline Gly1011Arg & DACM & 1 & {$[32]$} & Surface exposed in a loop & 0.773 \\
\hline Tyr1014Cys & LGMD2B \& MM & 5 & {$[37,41]$} & Orientates Arg1038 in Stack 3. H bond $\mathrm{OH}$ to guanadinium & 1.000 \\
\hline Arg1022Gln & LGMD2B & 7 & {$[28,37]$} & Surface exposed. Poor side chain density & 0.312 \\
\hline Pro1029Leu & MM & 2 & {$[42]$} & Surface exposed & 0.062 \\
\hline Arg1038Gln & LGMD2B & 7 & {$[28,29,42,43]$} & In stack 3 & 1.000 \\
\hline Arg1039Trp & MM & 1 & [16] & Opposite face stack & 0.923 \\
\hline Arg1039Leu & MM & 1 & [44] & Opposite face stack & 0.923 \\
\hline Arg1041Cys & MM & 2 & [31] & Surface exposed. H bond to E952 & 0.617 \\
\hline Arg1044Ser & DAMT & 2 & {$[44]$} & In Stack 2 & 1.000 \\
\hline Arg1046His & MM & 11 & {$[42,45,46]$} & In Stack 1 & 0.386 \\
\hline
\end{tabular}

LGMD2B- Limb Girdle Muscular Dystrophy 2B. MM-Myoshi Myopathy, DAMT-Distal anterior Myopathy Tibial Onset, Conversation Score was calculated using alignment in Figure 1 and Scorecons program [47].

dysF domain were pooled together and treated with TEV protease for $20 \mathrm{~h}$ at $4^{\circ} \mathrm{C}$ to remove the histidine tag. Then the volume was decreased to $4 \mathrm{ml}$ by Vivaspin concentrator (Sartorius, Germany) with 5,000 Da molecular weight cutoff. The sample was further purified by size exclusion chromatography using Superdex 200 16/60 column (GE, Healthcare). The protein was purified further by anion exchange chromatography (Resource Q) on a gradient of $0-0.5 \mathrm{M} \mathrm{NaCl}$ in $20 \mathrm{mM}$ Tris, $\mathrm{pH} 7.5$, and $5 \mathrm{mM} \mathrm{2-mercaptoethanol.} \mathrm{The} \mathrm{protein} \mathrm{concentra-}$ tion was estimated using NanoDrop spectrophotometer at UV light absorbance at $280 \mathrm{~nm}$ (absorbance coefficient $\left.=45950 \mathrm{M}^{-1} \mathrm{~cm}^{-1}\right)$. The protein sample was concentrated to $10 \mathrm{mg} / \mathrm{ml}(750 \mu \mathrm{M})$ in final buffer
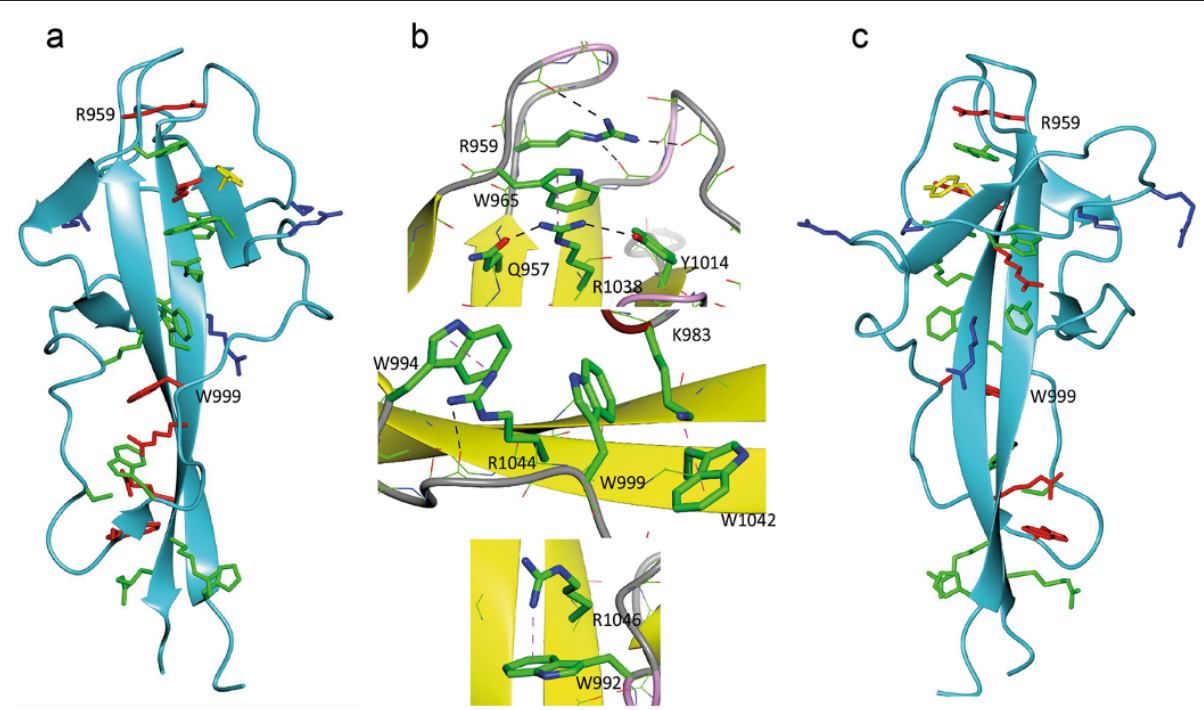

Figure 4 Missense mutations mapped onto DysF domain structure. (a and c) Ribbon representation showing W/R stack rotated 180 degrees about the $y$ axis of the page; mutated residues implicated in stack formation (red), mutated residues in the surface (blue), mutated residues stabilising the arginines involved in stack formation (yellow). Other residues of the W/R stack are in green. (b): Interaction and environment of the most common pathogenic mutations (R959, W999 and R1046). H bonds shown as black dotted lines and stacking interactions as magenta dotted lines. Figure drawn with CCP4mg [19]. 
(20 mM Tris- $\mathrm{HCl}, \mathrm{pH} 7.5,120 \mathrm{mM} \mathrm{NaCl}$, and $5 \mathrm{mM}$ 2-mercaptoethanol) and used for crystallisation trials.

\section{Protein crystallisation and structure determination}

The inner DysF domain was screened for crystallisation at $16^{\circ} \mathrm{C}$, by the sitting-drop method in 96 - well crystallisation plates (Molecular Dimensions), using PACT screen [49]. After 11 days, small crystals appeared in a drop with mother liquor consisting of $0.2 \mathrm{M} \mathrm{NaBr}$ and 20\% PEG 3350. This crystallisation could not be reproduced initially. $0.2 \mathrm{M} \mathrm{NaBr}$ was then added to the protein sample and the crystallisation screen was done again. Bigger crystals were produced in one day, where the reservoir contained $0.04 \mathrm{M}$ potassium dihydrogen phosphate, 16\% w/v PEG 8000 and 20\% v/v Glycerol. $0.3 \mathrm{~mm}$ cubic crystals were grown by the hanging drop method based on this condition. The crystal was cryoprotected in crystallisation buffer with the glycerol concentration increased to $25 \%$. Initial diffraction data was collected to $2.3 \AA$ in house using MicroMax TM -007 rotating anode X-ray generator $(\lambda=1.54 \AA)$ and Saturn 944+ CCD detector with Varimax optics. Further data was collected at Soleil beamline proxima 1 and at beam ID29 at ESRF. Diffraction images were processed using XDS software package [50], and scaled using aimless in the CCP4 program suite [51]. The initial phases of the dysferlin inner DysF domain were determined by molecular replacement with the program Mr Bump [52] using human myoferlin inner DysF domain [18] [PDB:2K2O] as the search model. The model was manually rebuilt in COOT [53] and refined initially in Refmac [54] and then continued in PHENIX [55]. Data collection and refinement statistics are summarized in Table 1.

No human subjects were directly used in this study. Human mutation data was taken from publicly accessible databases.

\section{Abbreviations \\ Å: Ångstrom (10-10 m); CING: Common Interface for NMR structure Generation; EDTA: Ethylenediaminetetraacetic acid; IPTG: Isopropyl $\beta$-D-1-thiogalactopyranoside; LB: Luria broth; NMR: Nuclear magnetic resonance; RMSD: Root mean square deviation; R/W: Arginine/Tryptophan stacks; TEV: Tobacco etch virus.}

\section{Competing interests}

The authors declare that they have no competing interest.

\begin{abstract}
Authors' contributions
AS prepared the expression construct and protein, grew the crystals and carried out the refinement and drew most of the figures. AC collected the diffraction data and advised on crystallisation. CY and CO defined the domain boundaries and the multiple domain architecture. NK wrote the first draft of the manuscript. CO and NK devised the project and trained AS All authors have read and agreed the final manuscript.
\end{abstract}

\section{Acknowledgements}

AS is supported by a Biotechnology and Biological Research Council (BBSRC) studentship BB/F016948/1. We thank the Jain Foundation for the gift of human dysferlin cDNA and Dr Opher Gileadi of the Structural Genomics Consortium for the gift of pNic28Bsa4.

\section{Author details}

${ }^{1}$ Crystallography, Biological Sciences, Institute for Structural and Molecular Biology, Birkbeck University of London, Malet Street, London WC1E 7HX, UK ${ }^{2}$ Structural \& Molecular Biology, Darwin Building, Institute for Structural and Molecular Biology, University College London, Gower Street, London WC1E 6BT, UK. ${ }^{3}$ Current Address: Infectious Disease Epidemiology, Imperial College London, St Mary's Campus, Norfolk Place, London W2 1PG, UK.

Received: 12 November 2013 Accepted: 15 January 2014

Published: 17 January 2014

\section{References}

1. Bashir R, Britton S, Strachan T, Keers S, Vafiadaki E, Lako M, Richard I, Marchand S, Bourg N, Argov Z, et al: A gene related to Caenorhabditis elegans spermatogenesis factor fer- 1 is mutated in limb-girdle muscular dystrophy type 2B. Nat Genet 1998, 20:37-42.

2. Liu J, Aoki M, Illa I, Wu C, Fardeau M, Angelini C, Serrano C, Urtizberea JA Hentati F, Hamida MB, et al: Dysferlin, a novel skeletal muscle gene, is mutated in Miyoshi myopathy and limb girdle muscular dystrophy. Nat Genet 1998, 20:31-36.

3. Illa I, Serrano-Munuera C, Gallardo E, Lasa A, Rojas-García R, Palmer J, Gallano P, Baiget M, Matsuda C, Brown RH: Distal anterior compartment myopathy: a dysferlin mutation causing a new muscular dystrophy phenotype. Ann Neurol 2001, 49:130-134.

4. Bansal D, Miyake K, Vogel SS, Groh S, Chen CC, Williamson R, McNeil PL, Campbell KP: Defective membrane repair in dysferlin-deficient muscular dystrophy. Nature 2003, 423:168-172.

5. Bansal D, Campbell KP: Dysferlin and the plasma membrane repair in muscular dystrophy. Trends Cell Biol 2004, 14:206-213.

6. Lek A, Evesson FJ, Sutton RB, North KN, Cooper ST: Ferlins: regulators of vesicle fusion for auditory neurotransmission, receptor trafficking and membrane repair. Traffic 2012, 13:185-194.

7. Lek A, Lek M, North KN, Cooper ST: Phylogenetic analysis of ferlin genes reveals ancient eukaryotic origins. BMC Evolutionary Biology 2010, 10:231.

8. Cuff AL, Sillitoe I, Lewis T, Clegg AB, Rentzsch R, Furnham N, Pellegrini-Calace M, Jones D, Thornton J, Orengo CA: Extending CATH: increasing coverage of the protein structure universe and linking structure with function. Nucleic Acids Res 2011, 39:D420-D426.

9. Letunic I, Doerks T, Bork P: SMART 7: recent updates to the protein domain annotation resource. Nucleic Acids Res 2012, 40:D302-D305.

10. Punta M, Coggill PC, Eberhardt RY, Mistry J, Tate J, Boursnell C, Pang N, Forslund K, Ceric G, Clements J, et al: The Pfam protein families database. Nucleic Acids Res 2012, 40:D290-D301.

11. Davis DB, Doherty KR, Delmonte AJ, McNally EM: Calcium-sensitive phospholipid binding properties of normal and mutant ferlin C2 domains. J Biol Chem 2002, 277:22883-22888.

12. Therrien C, Di Fulvio S, Pickles S, Sinnreich M: Characterization of lipid binding specificities of dysferlin C2 domains reveals vovel interactions with phosphoinositides. Biochemistry 2009, 48:2377-2384.

13. Xu L, Pallikkuth S, Hou Z, Mignery GA, Robia SL, Han R: Dysferlin forms a dimer mediated by the $\mathrm{C} 2$ domains and the transmembrane domain in vitro and in living cells. PloS one 2011, 6:e27884-e27884.

14. Fuson K, Rice A, Mahling R, Snow A, Nayak K, Shanbhogue P, Meyer Austin G, Redpath GMI, Hinderliter A, Cooper ST, Sutton RB: Alternate Splicing of Dysferlin C2A Confers Ca2+-Dependent and Ca2+-Independent Binding for Membrane Repair. Structure 2014. In press.

15. Aartsma-Rus A, Van Deutekom JCT, Fokkema IF, Van Ommen GJB, Den Dunnen JT: Entries in the Leiden Duchenne muscular dystrophy mutation database: an overview of mutation types and paradoxical cases that confirm the reading-frame rule. Muscle Nerve 2006, 34:135-144.

16. Leiden muscular dystrophy database dysferlin sequence variants. http://www.dmd.nl/dysf seqvar.html.

17. Ponting CP, Mott R, Bork P, Copley RR: Novel protein domains and repeats in Drosophila melanogaster: insights into structure, function, and evolution. Genome Res 2001, 11:1996-2008.

18. Patel P, Harris R, Geddes SM, Strehle EM, Watson JD, Bashir R, Bushby K, Driscoll PC, Keep NH: Solution structure of the inner DysF domain of 
myoferlin and implications for limb girdle muscular dystrophy type $2 \mathrm{~b}$. J Mol Biol 2008, 379:981-990.

19. McNicholas S, Potterton E, Wilson KS, Noble MEM: Presenting your structures: the CCP4mg molecular-graphics software. Acta Crystallogr D Biol Crystallogr 2011, 67:386-394.

20. Doreleijers JF, da Silva AWS, Krieger E, Nabuurs SB, Spronk C, Stevens TJ, Vranken WF, Vriend G, Vuister GW: CING: an integrated residue-based structure validation program suite. Journal of Biomolecular Nmr 2012, 54:267-283.

21. CING database RMS Data for $2 \mathrm{k} 2 \mathrm{o}$. http://nmr.cmbi.ru.nI/NRG-CING/data/ k2/2k2o/2k2o.cing/2k2o/Cing/2k2o_01_cv_rms.png.

22. Krissinel $E$, Henrick K: Inference of macromolecular assemblies from crystalline state. J Mol Biol 2007, 372:774-797.

23. Flocco MM, Mowbray SL: Planar stacking interactions of arginine and aromatic side-chains in proteins. J Mol Biol 1994, 235:709-717.

24. Ma JC, Dougherty DA: The cation-pi interaction. Chem Rev 1997, 97:1303-1324.

25. Singh J, Thornton JM: Atlas of Protein Side-Chain Interactions. Oxford: IRL Press; 1992.

26. Atlas of side chain interactions. http://www.ebi.ac.uk/thornton-srv/ databases/sidechains

27. Li AJ, Nussinov R: A set of van der Waals and Coulombic radii of protein atoms for molecular and solvent-accessible surface calculation, packing evaluation, and docking. Proteins-Structure Function and Genetics 1998, 32:111-127.

28. Cagliani R, Fortunato F, Giorda R, Rodolico C, Bonaglia MC, Sironi M, D'Angelo MG, Prelle A, Locatelli F, Toscano A, et al: Molecular analysis of LGMD-2B and MM patients: identification of novel DYSF mutations and possible founder effect in the Italian population. Neuromuscul Disord 2003, 13:788-795.

29. Cagliani R, Magri F, Toscano A, Merlini L, Fortunato F, Lamperti C, Rodolico C, Prelle A, Sironi M, Aguennouz M, et al: Mutation finding in patients with dysferlin deficiency and role of the dysferlin interacting proteins annexin A1 and A2 in muscular dystrophies. Hum Mutat 2005, 26:283.

30. Guglieri M, Magri F, D'Angelo MG, Prelle A, Morandi L, Rodolico C, Cagliani R, Mora M, Fortunato F, Bordoni A, et al: Clinical, molecular, and protein correlations in a large sample of genetically diagnosed Italian limb girdle muscular dystrophy patients. Hum Mutat 2008, 29:258-266.

31. Kawabe K, Goto K, Nishino I, Angelini C, Hayashi YK: Dysferlin mutation analysis in a group of Italian patients with limb-girdle muscular dystrophy and Miyoshi myopathy. Eur J Neurol 2004, 11:657-661.

32. Klinge L, Aboumousa A, Eagle M, Hudson J, Sarkozy A, Vita G, Charlton R, Roberts M, Straub V, Barresi R, et al: New aspects on patients affected by dysferlin deficient muscular dystrophy. J Neurol Neurosurg Psychiatry 2010, 81:946-953.

33. de Luna N, Gallardo E, Soriano M, Dominguez-Perles R, de la Torre C, Rojas-Garcia R, Garcia-Verdugo JM, Illa I: Absence of dysferlin alters myogenin expression and delays human muscle differentiation "in vitro". J Biol Chem 2006, 281:17092-17098

34. Fanin M, Nascimbeni AC, Angelini C: Muscle protein analysis in the detection of heterozygotes for recessive limb girdle muscular dystrophy type 2B and 2E. Neuromuscul Disord 2006, 16:792-799.

35. Kesari A, Fukuda M, Knoblach S, Bashir R, Nader GA, Rao D, Nagaraju K, Hoffman EP: Dysferlin deficiency shows compensatory induction of Rab27A/SIp2a that may contribute to inflammatory onset. Am J Pathol 2008, 173:1476-1487.

36. Cho HJ, Sung DH, Kim EJ, Yoon CH, Ki CS, Kim JW: Clinical and genetic analysis of Korean patients with Miyoshi myopathy: identification of three novel mutations in the DYSF gene. J Korean Med Sci 2006, 21:724-727.

37. Hattori H, Nagata E, Oya Y, Takahashi T, Aoki M, Ito D, Suzuki N: A novel compound heterozygous dysferlin mutation in Miyoshi myopathy siblings responding to dantrolene. Eur J Neurol 2007, 14:1288-1291.

38. Tagawa K, Ogawa M, Kawabe K, Yamanaka G, Matsumura T, Goto K, Nonaka I, Nishino I, Hayashi YK: Protein and gene analyses of dysferlinopathy in a large group of Japanese muscular dystrophy patients. J Neurol Sci 2003, 211:23-28.

39. Takahashi T, Aoki M, Tateyama M, Kondo E, Mizuno T, Onodera Y, Takano R Kawai H, Kamakura K, Mochizuki $\mathrm{H}$, et al: Dysferlin mutations in Japanese Miyoshi myopathy: relationship to phenotype. Neurology 2003, 60:1799-1804.

40. Matsuda C, Hayashi YK, Ogawa M, Aoki M, Murayama K, Nishino I, Nonaka I, Arahata K, Brown RH: The sarcolemmal proteins dysferlin and caveolin-3 interact in skeletal muscle. Hum Mol Genet 2001, 10:1761-1766.
41. Rosales XQ, Gastier-Foster JM, Lewis S, Vinod M, Thrush DL, Astbury C, Pyatt R, Reshmi S, Sahenk Z, Mendell JR: Novel diagnostic features of dysferlinopathies. Muscle Nerve 2010, 42:14-21.

42. Krahn M, Wein N, Lostal W, Bourg-Alibert N, Nguyen K, Courrier S, Vial C, Labelle V, De Petris D, Borges A, et al: Partial functionality of a mini-dysferlin molecule identified in a patient affected with moderately severe primary dysferlinopathy. Neuromuscul Disord 2008, 18:781-781.

43. Nagaraju K, Rawat R, Veszelovszky E, Thapliyal R, Kesari A, Sparks S, Raben N, Plotz P, Hoffman EP: Dysferlin deficiency enhances monocyte phagocytosis: a model for the inflammatory onset of limb-girdle muscular dystrophy 2B. Am J Pathol 2008, 172:774-785.

44. de Luna N, Gallardo E, Soriano M, Dominguez-Perles R, de la Torre C, Rojas-Garcia R, Garcia-Verdugo JM, Illa I: Absence of dysferlin alters myogenin expression and delays human muscle differentiation 'in vitro'. Neuromuscul Disord 2006, 16:S57-S57.

45. Nguyen K, Bassez G, Eymard B, Levy N, Pouget J: Phenotypic and genetic analysis in a series of 55 patients with dysferlinopathy. Neurology 2005, 64:A413-A414.

46. Aoki M, Takahashi T: Mutational and clinical features of Japanese patients with dysferlinopathy (Miyoshi myopathy and limb girdle muscular dystrophy type 2B). Rinsho shinkeigaku = Clinical neurology 2005, 45:938-942.

47. Valdar WS: Scoring residue conservation. Proteins 2002, 48:227-241

48. Savitsky P, Bray J, Cooper CD, Marsden BD, Mahajan P, Burgess-Brown NA, Gileadi O: High-throughput production of human proteins for crystallization: the SGC experience. I Struct Biol 2010, 172:3-13.

49. Newman J, Egan D, Walter TS, Meged R, Berry I, Ben Jelloul M, Sussman JL, Stuart DI, Perrakis A: Towards rationalization of crystallization screening for small- to medium-sized academic laboratories: the PACT/JCSG+ strategy. Acta Crystallogr D Biol Crystallogr 2005, 61:1426-1431.

50. Kabsch W: XDS. Acta Crystallogr D Biol Crystallogr 2010, 66:125-132.

51. Evans PR: An introduction to data reduction: space-group determination, scaling and intensity statistics. Acta Crystallographica Section D-Biological Crystallography 2011, 67:282-292.

52. Keegan RM, Winn MD: MrBUMP: an automated pipeline for molecular replacement. Acta Crystallographica Section D-Biological Crystallography 2008, 64:119-124.

53. Emsley P, Lohkamp B, Scott WG, Cowtan K: Features and development of Coot. Acta Crystallogr D Biol Crystallogr 2010, 66:486-501.

54. Murshudov GN, Vagin AA, Dodson EJ: Refinement of macromolecular structures by the maximum-likelihood method. Acta Crystallogr D Biol Crystallogr 1997, 53:240-255.

55. Adams PD, Afonine PV, Bunkóczi G, Chen VB, Davis IW, Echols N, Headd JJ, Hung LW, Kapral GJ, Grosse-Kunstleve RW, et al: PHENIX: a comprehensive Python-based system for macromolecular structure solution. Acta Crystallogr D Biol Crystallogr 2010, 66:213-221.

doi:10.1186/1472-6807-14-3

Cite this article as: Sula et al:: Crystal structures of the human Dysferlin inner DysF domain. BMC Structural Biology 2014 14:3.

\section{Submit your next manuscript to BioMed Central and take full advantage of:}

- Convenient online submission

- Thorough peer review

- No space constraints or color figure charges

- Immediate publication on acceptance

- Inclusion in PubMed, CAS, Scopus and Google Scholar

- Research which is freely available for redistribution 